\title{
Effectiveness of combined and conventional exercise trainings on the biochemical responses of stroke patients
}

\author{
Isaac Kwaku Acheampong, Monday Omoniyi Moses*, Biggie Baffour-Awuah, Ebenezer Essaw, Winifred Mensah, Daniel Afrifa, \\ Lemuel Owusu
}

Department of Sports and Exercise Science, Faculty of Allied Health Sciences, College of Health Sciences, Kwame Nkrumah University of Science and Technology, Kumasi, Ghana

Stroke is the topmost cause of mortality and disability in Ghana. Conventional exercise is mostly used aside pharmacological management technique but the complimentary effects of combined exercise training (CET) have not been reported. This study investigated the effectiveness of combined and conventional exercise trainings on lipid-cardiovascular profiles and body composition among stroke patients in Kumasi. Thirteen stroke survivors between ages $35-68$ years (mean \pm standard deviation: age, $59.88 \pm 10.88$ years; duration of illness, $18.11 \pm 7.72$ years) participated in the study. Participants were randomly assigned to CET and conventional exercise group. The CET had 10 weeks of 3 types of exercise trainings, 3 days/wk; conventional exercise group monitored for daily conventional activities during the same period. Post weight $(P=$ $0.003)$, body mass index $(P=0.004)$, systolic blood pressure $(P=0.022)$, diastolic blood pressure $(P=0.004)$, heart rate $(P=0.003)$, and total cholesterol $(P=0.044)$ of the CET were significantly improved. CET significantly improved total cholesterol $(P=0.005)$ and low-density lipoprotein $(P=0.006)$ better than the conventional exercises. Effectiveness of CET to positively enhance biochemical responses in the management of strove patients was established.

Keywords: Stroke patients, Flexibility exercise, Aerobic exercise, Resistance exercise, Lipid, Blood pressure

\section{INTRODUCTION}

Currently stroke is defined as classically characterized as a neurological deficit attributed to an acute focal injury of the central nervous system by a vascular cause, including cerebral infarction, intracerebral hemorrhage, and subarachnoid hemorrhage, and is a major cause of disability and death worldwide (Sacco et al., 2013). Globally, stroke is a cerebrovascular disease principally as the second foremost source of death and a notable contributory factor to disability and reduction in quality of life especially among adult (Hopewell and Clarke, 2016; Murray et al., 2001). Six point seven (6.7) million stroke associated deaths estimated parts of the total 17.5 million dead (31.0\% of all global deaths) caused by cardiovascular diseases in 2015 (World Health Organization, 2015). Over the past few decades, stroke incidence has fallen in developed countries, but increased more than $100 \%$ in developing countries (Feigin et al., 2009). For the past years, the burden of stroke seems to be widespread in developing countries and with two-thirds of stroke death cases occurring in sub-Saharan Africa. Stroke data of sub-Saharan Africa indicates an annual stroke occurrence rate of up to 316 per 100,000, a prevalent rate of 315 per 100,000 and a mortality rate of $84 \%$ (Truelsen et al., 2007). Sub-Saharan Africa recorded about half a million (4.4\%) stroke deaths in 2012 of all deaths in the region (Africa Check, 2015). Stroke was the fourth leading cause of death among the top 10 killer diseases in Ghana in the year 2009 according to Centers for Disease Control and Prevention (2010). Currently stroke ranks among the top three causes of mortality, and is probably the most prevalent cause of disability in Ghana, as in other developing countries (World Life Expectancy, 2015). According to a study in 2011, $7.34 \%$ of all

\footnotetext{
${ }^{*}$ Corresponding author: Monday Omoniyi Moses

(iD) https://orcid.org/0000-0001-5785-9551

Department of Sports and Exercise Science, Faculty of Allied Health Sciences,

College of Health Sciences, Kwame Nkrumah University of Science and

Technology, Kumasi, Ghana

Tel: +233-547336905, Fax: +233-322060331, E-mail: mmomoniyi.chs@knust.edu.gh

Received: April 6, 2018 / Accepted: April 28, 2018
}

This is an Open Access article distributed under the terms of the Creative Commons Attribution Non-Commercial License (http://creativecommons.org/licenses/by-nc/4.0/) which permits unrestricted non-commercial use, distribution, and reproduction in any medium, provided the original work is properly cited. 
medical deaths occurred through stroke, the third leading causes of mortality in Ghana (World Life Expectancy, 2015). A year review of the records of Konfo Anokye Teaching Hospital in-patient showed that stroke contributed $13.2 \%$ to all medical adult deaths and $9.1 \%$ of total medical adult admissions (Agyemang et al., 2012). The study of Ofori-Asenso and Garcia (2016) showed that $5.7 \%, 32.7 \%$, and $43.2 \%$ of stroke related mortality occurred at $24 \mathrm{hr}, 7$ and 28 days respectively. There are two types of stroke: a bleed (haemorrhagic stroke) and a blockage (ischaemic stroke) (Silva et al., 2014). Haemorrhagic stroke happens when a blood vessel in the brain bursts and spills blood into or around the brain whiles ischaemic stroke is the common type of stroke, caused by the formation of blood clots in a main artery to the brain (National Association of Stroke, 2013). The risk factors of stroke can be grouped into two; risk factors that are nonmodifiable and those that are modifiable. The nonmodifiable risk factors include genetics, gender and age whiles the modifiable risk factors include factors such as sedentary life style, abnormal blood lipids, high blood pressure, diabetes, obesity, lipoproteins and cigarette smoking (Lopez et al., 2006; O’Donnell et al., 2010).

Exercise, as any physical activity that is planned, structured, and repetitively done for the purpose of conditioning any part of the body and also used to improve health; maintain fitness and as a means of physical rehabilitation (Caspersen et al., 1985), has been a major component of management of stroke survivors worldwide, along with diet and medication (Smith et al., 2001; Wolf et al., 1999). Studies involving stroke and able-bodied subjects have documented the useful impart of regular physical activity on several cardiovascular disease risk factors and provided evidence that such benefits are likely to translate into a reduced risk for mortality from stroke and cardiac events (Prout et al., 2017). In this study, the normally employed activities like walking, standing, siting and bending, mostly accepted as forms of exercise for many stroke survivors as a result of inadequate exercise scientists to prescribe exercise, are referred to as conventional exercise. According to Munneke et al. (2004), any form of physical activities with low impact isometric exercises and "range of motion" exercises are known as Conventional exercises programs. In view of economic restraints, it is important to establish effective and economic stroke programs which address stroke prevention and management. There are many comparative studies which used single exercise groups, conventional treatment groups, and non exercise control groups for stroke patient (Shin et al., 2011) but showed no statistical significant improvement.

Combined exercises are two or more exercise that is used in re- habilitation for example; aerobic exercise together with resistance (strength) and flexibility exercises (Marzolini et al., 2014). Combined exercise training (CET) that mixes strengthening, aerobic, gait, and balance training has been studied (Shin et al., 2011). This type of training increased balance, muscle strength and ability to prevent falls in comparison to conventional and single bout of exercise (Englund et al., 2005). However, CET research is less and calls for more research on stroke patients (Shin et al., 2011). Looking at the trend, it is clearly seen that stroke is a major cause of morbidity and disability in Kumasi, Ghana. Presently, Ghana produces marginal experts (i.e., exercise scientist, physiotherapist, language therapist, physical therapist, etc.) in the few rehabilitation facilities. The use of combined exercise in the management of stroke survivors in Ghana remains limited. It is therefore anticipated that CET will have significant impact on the biochemical responses of stroke survivors in Kumasi, Ghana.

The following objectives were set; to determine the blood pressure, body mass index (BMI), total cholesterol (TC), high-density lipoprotein (HDL), low-density lipoprotein (LDL), and triglycerides (TG) of the combined exercise and conventional exercise groups at pre and post levels; to compare the blood pressure and BMI, TC, HDL, LDL, and TG of the combined and conventional exercise groups.

\section{MATERIALS AND METHODS}

\section{Study design and setting}

The study adopted a classical pretest-posttest experimental design. Participants were grouped into combined and control exercise training groups. The CET group that served as the intervention group was blinded from the conventional exercise group that was the control group. This study was conducted at the physiotherapy units of two hospitals (Living Waters and Aniwaa Medical Center) in the Kumasi Metropolis Ghana. Ethical clearance was obtained from the Committee of Human Research Publications and Ethics at the School of Medical Sciences, Kwame Nkrumah University of Science and Technology (Ref: CHRPE/AP/237/ 17). All the participants signed written informed consent form.

\section{Sampling technique}

A total of 25 participants with known cases of stroke were contacted for eligibility to participate in the study. Twenty-one who met the inclusion and exclusion criteria were randomized into one treatment group (CET group, $\mathrm{n}=10$ ) and (conventional control group, $\mathrm{n}=11$ ). Out of the 20 stroke patients, only $65.0 \%$ (13) 
fully participated and completed all the sections of the study. Of the 13 , five ( 2 females and 3 males) were in the CET group while eight ( 6 females and 2 males) were in the conventional group. The five who completed the CET were (a) between the age group of 25-68 years, (b) diagnosed with stroke for less than 2 years, (c) present with either hypertensive or diabetic stroke or both, (d) on oral hypoglycemic, antihypertensive and others both drugs, and (e) cleared of severe complications (e.g., blindness, kidney, and nerve damage). The study excluded stroke patients with (a) systolic (SBP) and diastolic blood pressure (DBP) more than 160 and 110 $\mathrm{mmHg}$ respectively, (b) pre-existing disease or medical conditions that made their participation inadvisable, and (c) who were undergoing any exercise program.

\section{Measurement}

Pre-post intervention data on the biochemical variables (TC, HDL, LDL, and TG), physiological variables (BMI and body weight) and cardiovascular variables (SBP and DBP) were collected with standardize instruments. Mindray chemistry analyzer (BS 120, Shenzhen Mindray Bio-Medical Electronics Co., Ltd., Shenzhen, China) was used to analyze the lipid profiles (TC, HDL, LDL, and TG). Digital blood pressure monitor (Omron Healthcare Co. Ltd., Kyoto, Japan) was used for physiological measurements: heart rate (HR), SBP, DBP of subjects from left arm; and weight of participants in kg. Health-O-meter (model BSM 370, Biospace China Inc., Shanghai, China) was used to measure height in meters. BMI in $\mathrm{kg} / \mathrm{m}^{2}$ was calculated using the values of weight $(\mathrm{kg})$ and height $(\mathrm{m})$ - formula: weight/(height $)^{2}$. Data collection form (researcher's own construct) was used to collect demographic information (age, marital status, and gender, diagnosis and duration of illness) of participants, physiological profiles (HR, SBP, and DBP), drug history (duration of medication and specific drug used) and anthropometric measurements (weight, height, and BMI). We collected preintervention data on a Saturday proceeding the Monday of the week of the commencement of CET and kept as a baseline data. At the Saturday of the last week of the CET, post data collection was carried out.

\section{Intervention}

The 10 weeks CET started with ten minutes warm ups and cool down sessions throughout each of the training periods. CET consisted of aerobic exercise training, flexibility exercise training and resistance exercise training sessions (Table 1). Walking and bicycle riding over designated time were the components of aerobic exercise training. Static and dynamic stretching exercises such

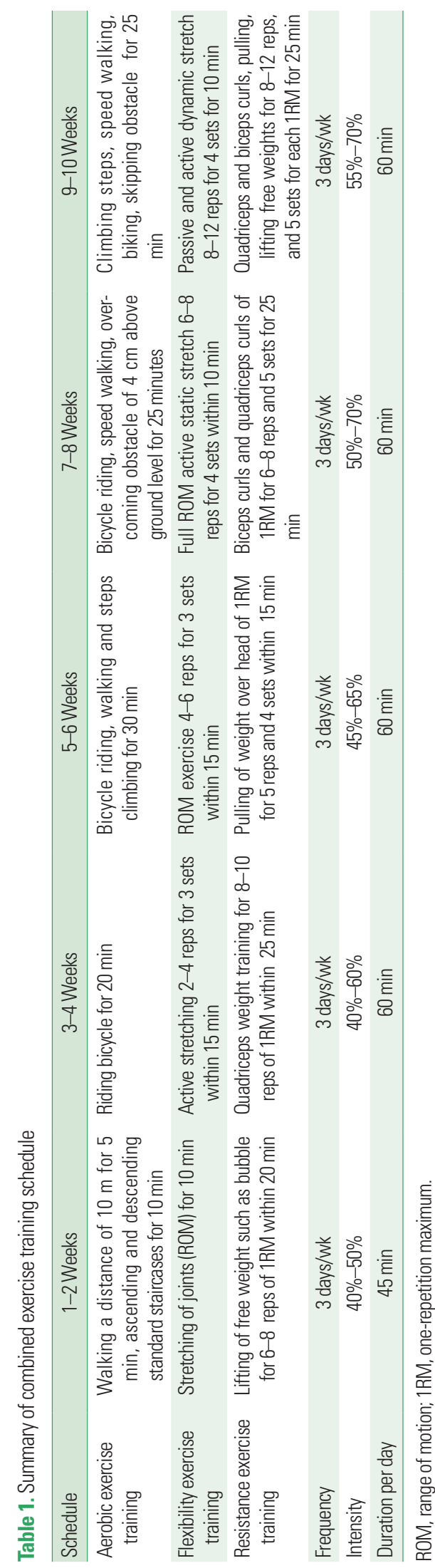


as trunk rotation, flexion, and extension; hip movements; standing hamstring stretch; plantar flexors, dorsi flexors; shoulder, wrist and neck movements; and squatting formed the flexibility exercises. Lifting of free weight such as bubble, repetitive quadriceps weight training, pulling of weight overhead, biceps and quadriceps curls were resistance training activities. CET frequency consisted of 3 days contact per week at the intensity that ranged between $40 \%-70 \%$ of maximum HR. The targeted HR was determined using Polar H10 HR monitor. Each of the sessions lasted between 45 and $60 \mathrm{~min}$. The principle of progressive overload was employed over the course of the training period. The participants in the conventional exercise group were instructed not to embark on any exercise sessions aside activities of daily living for the same period of study and were monitored.

\section{Statistical analysis}

Statistical analysis was done by using IBM SPSS Statistics version 23.0 (IBM Co., Armonk, NY, USA). Descriptive statistics of means, standard deviation, and paired $t$-test was used to present changes in TC, triglyceride, HDL, and LDL to compare differences in parameters before and after the exercise program, while a mixed-design two-way analysis of variance was also used to compare between group difference for all the variables before and after exercise all set at $P<0.05$ level of significance.

\section{RESULTS}

In the present study, five stroke patients participated in CET whereas eight completed convectional exercise. There was a reduction in the percent mean difference for all variables as shown in

Table 2. Differences in the pre-post combined exercise group

\begin{tabular}{|c|c|c|c|c|c|c|}
\hline Variable & Pre & Post & $\%$ Mean difference & $95 \% \mathrm{Cl}$ & $T$-value & $P$-value \\
\hline Weight (kg) & $77.84 \pm 4.71$ & $74.94 \pm 3.99$ & 3.73 & $1.61-4.19$ & 6.225 & $0.003^{*}$ \\
\hline BMI (kg/m²) & $28.31 \pm 2.43$ & $27.26 \pm 2.17$ & 3.71 & $0.58-1.54$ & 6.102 & $0.004^{*}$ \\
\hline $\mathrm{SBP}(\mathrm{mmHg})$ & $139.80 \pm 13.90$ & $126.20 \pm 7.82$ & 9.73 & $3.15-24.05$ & 3.614 & $0.022^{*}$ \\
\hline $\mathrm{DBP}(\mathrm{mmHg})$ & $91.40 \pm 5.59$ & $75.60 \pm 4.98$ & 17.29 & 8.59-23.01 & 6.086 & $0.004^{*}$ \\
\hline $\mathrm{RHR}$ (bpm) & $80.40 \pm 6.80$ & $77.00 \pm 6.60$ & 4.23 & $1.98-4.82$ & 6.668 & $0.003^{*}$ \\
\hline $\mathrm{TC}$ (mmol) & $3.766 \pm 1.08$ & $3.46 \pm 0.87$ & 8.13 & $0.01-0.60$ & 2.908 & $0.044^{*}$ \\
\hline $\mathrm{HDL}$ (mmol) & $1.238 \pm 0.26$ & $1.178 \pm 0.23$ & 4.85 & $-0.30-0.42$ & 0.467 & 0.665 \\
\hline $\mathrm{TG}$ (mmol) & $1.11 \pm 0.28$ & $1.05 \pm 0.23$ & 5.41 & $-0.00-0.12$ & 2.631 & 0.058 \\
\hline LDL (mmol) & $2.258 \pm 1.15$ & $1.914 \pm 0.77$ & 15.23 & $-0.13-0.82$ & 2.00 & 0.116 \\
\hline VLDL (mmol) & $0.504 \pm 0.12$ & $0.366 \pm 0.22$ & 27.38 & $-0.17-0.45$ & 1.243 & 0.282 \\
\hline
\end{tabular}

Values are presented as mean \pm standard deviation unless otherwise indicated.

$\mathrm{Cl}$, confidence interval; BMI, body mass index; SBP, systolic blood pressure; DPB, diastolic blood pressure; RHR, resting heart rate; TC, total cholesterol; HDL, high-density lipoprotein; TG, triglycerides; LDL, low-density lipoprotein; VLDL, very low-density lipoprotein.

${ }^{*} P<0.05$, statistical significance.

Table 3. Differences in the pre-post convectional exercise group

\begin{tabular}{|c|c|c|c|c|c|c|}
\hline Variable & Pre & Post & \% Mean difference & $95 \% \mathrm{CL}$ & $T$-value & $P$-value \\
\hline Weight (kg) & $68.43 \pm 8.00$ & $67.86 \pm 8.00$ & 1.19 & $-0.92-2.05$ & 0.896 & 0.400 \\
\hline $\mathrm{BMI}\left(\mathrm{kg} / \mathrm{m}^{2}\right)$ & $27.09 \pm 8.00$ & $26.91 \pm 8.00$ & 2.40 & $-0.39-0.74$ & 0.74 & 0.483 \\
\hline $\mathrm{SBP}(\mathrm{mmHg})$ & $136.50 \pm 8.00$ & $142.13 \pm 8.00$ & 3.02 & $-18.69-7.44$ & -1.018 & 0.343 \\
\hline $\mathrm{DBP}(\mathrm{mmHg})$ & $79.88 \pm 8.00$ & $78.25 \pm 8.00$ & 2.57 & $-5.18-8.43$ & 0.565 & 0.590 \\
\hline RHR (bpm) & $82.88 \pm 8.00$ & $77.63 \pm 8.00$ & 7.64 & $-2.95-13.45$ & 1.514 & 0.174 \\
\hline $\mathrm{TC}$ (mmol) & $5.15 \pm 8.00$ & $5.75 \pm 8.00$ & 11.65 & $-2.11-0.90$ & -0.954 & 0.372 \\
\hline $\mathrm{HDL}$ (mmol) & $1.22 \pm 8.00$ & $1.21 \pm 8.00$ & -0.82 & $-0.25-0.27$ & 0.079 & 0.940 \\
\hline TG (mmol) & $1.61 \pm 8.00$ & $1.73 \pm 8.00$ & 7.45 & $-1.31-1.06$ & -0.251 & 0.809 \\
\hline LDL (mmol) & $3.20 \pm 8.00$ & $3.80 \pm 8.00$ & 18.75 & $-2.09-0.89$ & -0.947 & 0.375 \\
\hline VLDL (mmol) & $0.73 \pm 8.00$ & $0.74 \pm 8.00$ & 1.37 & $-0.360-0.34$ & -0.068 & 0.948 \\
\hline
\end{tabular}

Values are presented as mean \pm standard deviation unless otherwise indicated.

$\mathrm{Cl}$, confidence interval; BMI, body mass index; SBP, systolic blood pressure; DPB, diastolic blood pressure; RHR, resting heart rate; TC, total cholesterol; HDL, high -density lipoprotein; TG, triglycerides; LDL, low- density lipoprotein; VLDL, very low-density lipoprotein. 
Table 2. Table 2 also showed significant paired differences in weight $(P=0.003)$, BMI $(P=0.004)$, SBP $(P=0.022)$, DBP $(P=0.004)$, HR $(P=0.003)$, and TC $(P=0.044)$ before and after CET session. Although insignificant, the percent reduction in the mean difference of all the variables was better in the CET group than the conventional exercise group (Tables 2, 3). When compared post differences between the groups, there was significant mean differences in TC (-2.29 and 0.005) and LDL (-1.90 and 0.006) of CET group than CG for as shown in Table 4. Combined exercise had significant difference on stroke patient's lipid profile, some cardiovascular profile and some body composition variables.

\section{DISCUSSION}

The present study investigated the effect of combined versus conventional exercise training on the biochemical responses of stroke patients. Initial baseline data was taken and compared with final data for both group. Clinical assessment of the experimental group showed significant paired differences between the pre and post values (weight, BMI, SBP, DBP, resting heart rate [RHR], and TC), but there was no significant difference in all the variables among the conventional group.

\section{Combined exercise and lipid profiles}

The results of this study showed a marginal reduction in lipid profile after the ten weeks of CET. The findings of this study confirmed studies that exercise reduces lipid profile even in stroke survivors (Kannan et al., 2014; Kim et al., 2014). Kim et al. (2014) investigated the effects of 12 weeks' regular exercise on the improvement of free fatty acid levels and metabolic risk factors of stroke patients. Significant reduction in TG, TC, and HDL cholesterol was observed (Kim et al., 2014).

According to Mann et al. (2014), regular physical activity and exercise can be utilized to enhance reduction in cholesterol levels. This study revealed a statistically mean difference in the Experimental group pre-post in percentage TC (8.13\%), HDL (4.85\%), TG (5.41\%), LDL (15.23\%), and very low-density lipoprotein (VLDL) (27.38\%). The study of Buttar et al. (2005) had earlier reported that exercise helps in controlling lipid profile levels in obesity women which is also one of the risk factors of cardiovascular disease especially stroke.

Another study by Kannan et al. (2014) that used 15 weeks of

Table 4. Difference in the post of combined exercise and convectional groups

\begin{tabular}{|c|c|c|c|c|c|c|}
\hline Variable & Group & Mean \pm SD & $\%$ Mean difference & $95 \% \mathrm{Cl}$ & T-value & $P$-value \\
\hline \multirow[t]{2}{*}{ Weight (kg) } & $\mathrm{EG}$ & $74.94 \pm 3.99$ & 9.45 & $-2.87-17.03$ & 1.565 & 0.146 \\
\hline & CG & $67.86 \pm 9.47$ & & & & \\
\hline \multirow[t]{2}{*}{$\mathrm{BMI}\left(\mathrm{kg} / \mathrm{m}^{2}\right)$} & EG & $27.26 \pm 2.17$ & 1.28 & $-3.37-4.06$ & 0.205 & 0.841 \\
\hline & CG & $26.91 \pm 3.33$ & & & & \\
\hline \multirow[t]{2}{*}{$\mathrm{SBP}(\mathrm{mmHg})$} & $\mathrm{EG}$ & $126.20 \pm 7.82$ & 12.62 & $-35.72-3.87$ & -1.811 & 0.103 \\
\hline & CG & $142.13 \pm 22.83$ & & & & \\
\hline \multirow[t]{2}{*}{$\mathrm{DBP}(\mathrm{mmHg})$} & $\mathrm{EG}$ & $75.60 \pm 4.98$ & 3.51 & $-11.72-6.42$ & -0.645 & 0.532 \\
\hline & CG & $78.25 \pm 9.77$ & & & & \\
\hline \multirow[t]{2}{*}{ RHR (bpm) } & $\mathrm{EG}$ & $77.00 \pm 6.60$ & 0.82 & $-10.92-9.67$ & -0.134 & 0.896 \\
\hline & CG & $77.63 \pm 8.99$ & & & & \\
\hline \multirow[t]{2}{*}{$\mathrm{TC}$ (mmol) } & EG & $3.46 \pm 0.87$ & 66.18 & $-3.72--0.8$ & -3.539 & $0.005^{*}$ \\
\hline & CG & $5.75 \pm 1.26$ & & & & \\
\hline \multirow[t]{2}{*}{$\mathrm{HDL}$ (mmol) } & EG & $1.18 \pm 0.23$ & 2.54 & $-0.34-0.28$ & -0.212 & 0.836 \\
\hline & CG & $1.21 \pm 0.25$ & & & & \\
\hline \multirow[t]{2}{*}{ TG (mmol) } & EG & $1.05 \pm 0.23$ & 64.76 & $-1.64-0.27$ & -1.656 & 0.137 \\
\hline & CG & $1.73 \pm 1.13$ & & & & \\
\hline \multirow[t]{2}{*}{ LDL (mmol) } & $\mathrm{EG}$ & $1.91 \pm 0.77$ & 108.37 & $-3.12--0.64$ & -3.348 & $0.006^{*}$ \\
\hline & CG & $3.80 \pm 1.09$ & & & & \\
\hline \multirow[t]{2}{*}{ VLDL (mmol) } & EG & $0.37 \pm 0.22$ & 100.00 & $-0.80-0.05$ & -1.939 & 0.079 \\
\hline & CG & $0.74 \pm 0.39$ & & & & \\
\hline
\end{tabular}

SD, standard deviation; Cl, confidence interval; EG, exercise group; CG, control group; BMI, body mass index; SPB, systolic blood pressure; DPB, diastolic blood pressure; RHR, resting heart rate; TC, total cholesterol; HDL, high -density lipoproteins; TG, triglycerides; LDL, low-density lipoproteins; VLDL, very low-density lipoprotein.

${ }^{*} P<0.05$, statistical significance. 
exercise to examine the variations in lipid profile of inactive obese adults varying for different intensity of exercise revealed a significant reduction difference in lipid profile. The reductions seen in TC, HDL, TG, LDL, and VLDL are possible effects of duration, Intensity and frequency of the exercise by means of physiological adaptations that can be attributed to the (decrease in fat cells, increase in muscle hypertrophy, increase in high metabolic activities of the cells, increase in oxygen consumption there by increasing the activity of the heart muscle and liver to convert a lot of fat into usable state for the body etc.). It can therefore be concluded that exercising for 10 weeks and above has effect on lipid profile even among stroke survivors.

\section{Combined exercise and cardiovascular profile}

Studies have reported significant reduction in SBP, DBP, and RHR among different populations following exercise training (Billinger et al., 2012; Shiraev and Barclay, 2012; Stoller et al., 2012). The results of this study were consistent with the reports of the above mentioned studies. Significant reductions were seen in SBP (0.022), DBP (0.004), and RHR (0.003) after the 10week exercise protocol. According to Billinger et al. (2012), in the search into the cause of such decline, he concluded that exercise has a significant impart in cardiovascular fitness especially by reducing SBP, DBP, and RHR. Stoller et al. (2012) administered cardiovascular exercise for 6 months to rehabilitate stroke survivals and reported statistically significant reduction in cardiovascular fitness during the acute phase of stroke. Though the findings of Stoller et al. (2012) were based on general cardiovascular fitness, the results of our study validate their outcomes. In AminShokravi et al. (2011), effects of a 12-week exercise program on the cardiovascular disease risk and fitness of Iranian middle aged women showed significant decrease in SBP and DBP. Another study carried out on the effects of aerobic exercise for 3 months on the cardiovascular profiles of trained and untrained athletes revealed that there were significant reductions in SBP, DBP, and RHR for the trained group (Sunita et al., 2015). According to Ammar (2015), afternoon aerobics exercise reduced both SBP and DBP significantly than morning in overweight hypertensive postmenopausal women after 12 weeks. Ammar (2015) further posited that the significant reductions seen in SBP, DBP, and RHR were possible effects of physiological adaptations (e.g., hypertrophy and strengthening of the cardiac muscle, increased stroke volume, increased lumen of blood vessels, etc.). We therefore conclude that exercising for 10 weeks and above has significant positive effect on cardiovascular profile even among stroke survivors.

\section{Combined exercise and body composition}

Most studies have shown a significant decrease in BMI and weight after weeks of regular exercise training. The statistical outputs of BMI (0.004) and weight (0.003) of this study significantly confirmed the findings of the above studies. Effective diet and aerobic exercise alone can cause minimal change in body weight and fat if greater than $250 \mathrm{~min} / \mathrm{wk}$ per day. Exercise training significantly induced weight loss and decreased BMI. Based on the consistency of the findings of this study with reported studies, we concluded that exercise training has a significant effect on weight and BMI and more especially among stroke survivors. From the findings of our study, combined exercise intervention group showed significant paired differences between the pre and post values of weight, BMI, SBP, DBP, resting HR, and TC. We therefore recommended that combination of monitored types of exercise such as aerobic, strength, resistance and flexibility be considered as a major component of stroke rehabilitation by healthcare providers in Ghana along pharmacological intervention and other necessary management strategies.

\section{CONFLICT OF INTEREST}

No potential conflict of interest relevant to this article was reported.

\section{ACKNOWLEDGMENTS}

Authors express our sincere appreciation to all the participants, management and staff of Living Waters Hospital and Aniwaa Medical Center. Our appreciations also go to Eric Junior APPIAH, Gwendoline Lady AKWA and Francis OSEI for advice and encouragement during the course of the study.

\section{REFERENCES}

Africa Check. Factsheet: The leading causes of death in Africa [Internet]. Johannesburg (South Africa): Africa Check; 2015 [cited 2015 Jun 9]. Available from: https://africacheck.org/factsheets/factsheet-the-leading-causes-of-death-in-africa/.

Agyemang C, Attah-Adjepong G, Owusu-Dabo E, De-Graft Aikins A, Addo J, Edusei AK, Nkum BC, Ogedegbe G. Stroke in Ashanti region of Ghana. Ghana Med J 2012;46(2 Suppl):12-17.

Amin-Shokravi F, Rajabi R, Ziaee N. Exercise effects on risk of cardiovascular disease among Iranian women. Asian J Sports Med 2011;2:37-43. Ammar T. Effects of aerobic exercise on blood pressure and lipids in 
overweight hypertensive postmenopausal women. J Exerc Rehabil 2015;11:145-150.

Billinger SA, Coughenour E, Mackay-Lyons MJ, Ivey FM. Reduced cardiorespiratory fitness after stroke: biological consequences and exercise-induced adaptations. Stroke Res Treat 2012;2012:959120.

Buttar HS, Li T, Ravi N. Prevention of cardiovascular diseases: role of exercise, dietary interventions, obesity and smoking cessation. Exp Clin Cardiol 2005;10:229-249.

Caspersen CJ, Powell KE, Christenson GM. Physical activity, exercise, and physical fitness: definitions and distinctions for health-related research. Public Health Rep 1985;100:126-131.

Centers for Disease Control and Prevention. CDD I Ghana. Factsheet [Internet]. Atlanta (GA): CDC; 2010 [cited 2016 May 11]. Available from: http://www.cdc.gov/globalhealth/countries/ghana/pdf/ghana- 2013. pdf.

Englund U, Littbrand H, Sondell A, Pettersson U, Bucht G. A 1-year combined weight-bearing training program is beneficial for bone mineral density and neuromuscular function in older women. Osteoporos Int 2005;16:1117-1123.

Feigin VL, Lawes CM, Bennett DA, Barker-Collo SL, Parag V. Worldwide stroke incidence and early case fatality reported in 56 populationbased studies: a systematic review. Lancet Neurol 2009;8:355-369.

Hopewell JC, Clarke R. Emerging risk factors for stroke: what have we learned from Mendelian randomization studies? Stroke 2016;47:16731678.

Kannan U, Vasudevan K, Balasubramaniam K, Yerrabelli D, Shanmugavel K, John NA. Effect of exercise intensity on lipid profile in sedentary obese adults. J Clin Diagn Res 2014;8:BC08-10.

Kim DY, Jung SY, Seo BD. Effect of exercise intervention on changes in free Fatty Acid levels and metabolic risk factors in stroke patients. J Phys Ther Sci 2014;26:275-279.

Lopez AD, Mathers CD, Ezzati M, Jamison DT, Murray CJ. Global and regional burden of disease and risk factors, 2001: systematic analysis of population health data. Lancet 2006;367:1747-1757.

Mann S, Beedie C, Jimenez A. Differential effects of aerobic exercise, resistance training and combined exercise modalities on cholesterol and the lipid profile: review, synthesis and recommendations. Sports Med 2014;44:211-221.

Marzolini S, Tang A, Mcllroy W, Oh PI, Brooks D. Outcomes in people after stroke attending an adapted cardiac rehabilitation exercise program: does time from stroke make a difference? J Stroke Cerebrovasc Dis 2014;23:1648-1656.

Munneke M, de Jong Z, Zwinderman AH, Ronday HK, van den Ende $\mathrm{CH}$, Vliet Vlieland TP, Hazes JM. High intensity exercise or conventional exercise for patients with rheumatoid arthritis? Outcome expec- tations of patients, rheumatologists, and physiotherapists. Ann Rheum Dis 2004;63:804-808.

Murray CJ, Lopez AD, Mathers CD, Stein C. The global burden of disease 2000 project: aims, methods and data sources. Global Programme on Evidence for Health Policy Discussion Paper No. 36. Geneva (Switzerland): World Health Organization; 2001.

National Association of Stroke. Explaining stroke [Internet]. Centennial (CO): National Association of Stroke; c2013 [cited 2017 May 20]. Available from: http://www.stroke.org/stroke-resources/resource-library/ explaining-stroke.

O'Donnell MJ, Xavier D, Liu L, Zhang H, Chin SL, Rao-Melacini P, Rangarajan S, Islam S, Pais P, McQueen MJ, Mondo C, Damasceno A, Lopez-Jaramillo P, Hankey GJ, Dans AL, Yusoff K, Truelsen T, Diener HC, Sacco RL, Ryglewicz D, Czlonkowska A, Weimar C, Wang X, Yusuf S; INTERSTROKE investigators. Risk factors for ischaemic and intracerebral haemorrhagic stroke in 22 countries (the INTERSTROKE study): a case-control study. Lancet 2010;376:112-123.

Ofori-Asenso R, Garcia D. Cardiovascular diseases in Ghana within the context of globalization. Cardiovasc Diagn Ther 2016;6:67-77.

Prout EC, Mansfield A, Mcllroy WE, Brooks D. Patients' perspectives on aerobic exercise early after stroke. Disabil Rehabil 2017;39:684-690.

Sacco RL, Kasner SE, Broderick JP, Caplan LR, Connors JJ, Culebras A, Elkind MS, George MG, Hamdan AD, Higashida RT, Hoh BL, Janis LS, Kase CS, Kleindorfer DO, Lee JM, Moseley ME, Peterson ED, Turan TN, Valderrama AL, Vinters HV; American Heart Association Stroke Council, Council on Cardiovascular Surgery and Anesthesia; Council on Cardiovascular Radiology and Intervention; Council on Cardiovascular and Stroke Nursing; Council on Epidemiology and Prevention; Council on Peripheral Vascular Disease; Council on Nutrition, Physical Activity and Metabolism. An updated definition of stroke for the 21st century: a statement for healthcare professionals from the American Heart Association/American Stroke Association. Stroke 2013;44:2064-2089.

Shin WS, Lee SW, Lee YW, Choi SB, Song CH. Effects of combined exercise training on balance of hemiplegic stroke patients. J Phys Ther Sci 2011;23:639-643.

Shiraev T, Barclay G. Evidence based exercise - clinical benefits of high intensity interval training. Aust Fam Physician 2012;41:960-962.

Silva AT, Dias MP, Calixto R Jr, Carone AL, Martinez BB, Silva AM, Honorato DC. Acute effects of whole-body vibration on the motor function of patients with stroke: a randomized clinical trial. Am J Phys Med Rehabil 2014;93:310-319.

Smith SC Jr, Blair SN, Bonow RO, Brass LM, Cerqueira MD, Dracup K, Fuster V, Gotto A, Grundy SM, Miller NH, Jacobs A, Jones D, Krauss RM, Mosca L, Ockene I, Pasternak RC, Pearson T, Pfeffer MA, Starke 
RD, Taubert KA. AHA/ACC Scientific Statement: AHA/ACC guidelines for preventing heart attack and death in patients with atherosclerotic cardiovascular disease: 2001 update: a statement for healthcare professionals from the American Heart Association and the American College of Cardiology. Circulation 2001;104:1577-1579.

Stoller O, de Bruin ED, Knols RH, Hunt KJ. Effects of cardiovascular exercise early after stroke: systematic review and meta-analysis. BMC Neurol 2012;12:45

Sunita C, Jayat K, Kamala C, Rajnee, Sonika CR. Effect of aerobic exercise on cardiovascular parameters in untrained and trained subjects. Sch J App Med Sci 2015;3(2A):538-542.

Truelsen T, Heuschmann PU, Bonita R, Arjundas G, Dalal P, Damasceno A, Nagaraja D, Ogunniyi A, Oveisgharan S, Radhakrishnan K, Skvortsoya VI, Stakhovskaya V. Standard method for developing stroke registers in low-income and middle-income countries: experiences from a feasibility study of a stepwise approach to stroke surveillance (STEPS Stroke). Lancet Neurol 2007;6:134-139.

Wolf PA, Clagett GP, Easton JD, Goldstein LB, Gorelick PB, Kelly-Hayes M, Sacco RL, Whisnant JP. Preventing ischemic stroke in patients with prior stroke and transient ischemic attack: a statement for healthcare professionals from the Stroke Council of the American Heart Association. Stroke 1999;30:1991-1994.

World Health Organization. Deaths from cardiovascular diseases and diabetes [Internet]. Geneva (Switzerland): World Health Organization; 2015 [cited 2017 May 2]. Available from: http://www.who.int/gho/ ncd/mortality_morbidity/cvd/en/.

World Life Expectancy. Health profile: Ghana [Internet]. World Life Expectancy; 2015 [cited 2017 May 20]. Available from: http://www.worldlifeexpectancy.com/country-health-profile/ghana. 